Article

\title{
Experimental Study on Hydraulic Characteristics of Pneumatic Lifting Pump
}

\author{
Juanli Zuo ${ }^{1, * \mathbb{D}}$, Fengchao $\mathrm{Li}^{2}{ }^{2}$, Ning Zhang ${ }^{3}$, Denghui He ${ }^{1}$, Wen Wang ${ }^{1}$ and Jie Zhang ${ }^{1}$ \\ 1 State Key Laboratory of Eco-hydraulics in Northwest Arid Region, Xi'an University of Technology, \\ Xi'an 710048, China; hedhui@foxmail.com (D.H.); wangwen1986@xaut.edu.cn (W.W.); \\ jiezhang@xaut.edu.cn (J.Z.) \\ 2 Science and Technology on Combustion, Internal Flow and Thermal-structure Laboratory, Northwestern \\ Polytechnical University, Xi'an 710072, China; 18392136924@163.com \\ 3 Intelligent Manufacturing Research and Development Center, Xijing University, Xi'an 710123, China; \\ zhangning@xijing.edu.cn \\ * Correspondence: Jenyzuo@163.com; Tel.: +86-1819-251-6705
}

Received: 20 December 2019; Accepted: 23 January 2020; Published: 1 February 2020

\begin{abstract}
A pneumatic lifting pump is used in sewage treatment, offshore oil production, and other fields because of its simple structure and strong practicability. In order to study its internal hydraulic characteristics and gas-liquid two-phase flow, this paper carries out experimental research on the influence of different air intake modes and riser diameters on the performance of a pneumatic lifting pump. The air-water two-phase flow pattern in the riser and motion characteristics of bubble formation at the nozzle are obtained by a high-speed camera. Through theoretical analysis, the theoretical model of a pneumatic lifting pump is established, and experimental results verify the theoretical model well. The results show that when the submergence ratio is constant, the lifting efficiency decreases with the smaller intake area under different intake areas; and the influences of different holes distributions on liquid flow rate and lifting efficiency are not significant under the same intake area. At the same submergence ratio, the smaller the riser diameter, the smaller the final lifting liquid flow rate and the larger the lifting efficiency peak value.
\end{abstract}

Keywords: pneumatic lifting pump; intake mode; riser diameter; experimental study

\section{Introduction}

Pneumatic lifting pump is a device which uses a compressor as its power source, takes air and liquid as working fluid, and conveys materials through multiphase flow in a pipe. It is advantaged for its simple structure and easy maintenance without any mechanical transmission parts, which can avoid related dynamic problems such as water hammer. Therefore, it is usually used on high-pressure, high-temperature, vacuum, radioactive, and corrosive liquids. Compared with mechanical pumps, pneumatic lifting pumps have lower maintenance costs and higher reliability [1]. At present, this type of pump is used in many fields, such as deep well water intake, sewage treatment, inland deep-sea mining, river dredging, and slag cleaning in steelmaking plants. Therefore, the study on lifting performance of pneumatic lifting pump and its internal hydraulic characteristics has a far-reaching impact on industrial development.

Carl Löscher first proposed the concept of a pneumatic lifting system, and the pneumatic lifting system was first used in an oil field in Pennsylvania, USA [2]. Kassab et al. [3] proposed a theoretical model to maximize operation efficiency of a pneumatic lifting pump. Pedram et al. [4] acquired the visual detection data of flow patterns in a pneumatic lifting pump with a high-speed camera. Pougatch et al. $[5,6]$ used multi-fluid Euler method to carry out two-dimensional numerical 
simulation. Esen [7] and Keng [8] mainly studied the influence of basic parameters on pneumatic lifting performance. Hanafizadeh $[9,10]$ and Charalampos [11,12] tested gas content and pressure distribution in a pipe and analyzed the stepped pipeline. Riglin [13] studied the effect of adding a helical component to a radial air incident device on pump performance. Sun Bo [14] and Liu Man [15] studied the two-phase flow process in the circular tube and the partial S-pipe of the pneumatic lifting pump. Hu et al. [16] studied the airlift pump performance in air-water-solid three-phase flow for conveying solid particles. Zou et al. [17] simulated the solid-liquid two-phase flow in pneumatic lifting system. Wahba et al. [18] observed the multiphase flow in a riser from the simplified one-dimensional analytical model to a large eddy simulation. Shigeo et al. [19] developed a small gas lifting pump with hydrofluorocarbon as working fluid. Xue et al. $[20,21]$ studied the void fraction and bubbly-slug flow pattern of air-water two-phase flow in vertically-downward pipes. Fu et al. [22] studied the flow pattern identification of gas-liquid two-phase flow and gas-liquid-solid three-phase flow in the riser of a pneumatic lifting pump. Oueslati [23] studied the effect of liquid temperature on the performance of the pump. An et al. [24] proposed a theoretical model of a bubble pump with a variable cross-section lift tube by the differential method. Wang et al. [25] presented a modified model to predict the performance of airlift pump operating in gas-liquid two-phase flow. Shi et al. [26] studied the lead bismuth alloy (LBE) circulation capability of gas lift pump on the natural circulation capability loop (NCCL) test facility. Chen et al. [27] set up a sediment transport test platform for pneumatic lifting technology. Qiang et al. [28] experimentally investigated the performance of an airlift pump through two lake experiments and one open sea trial. Shallouf et al. [29] simulated an airlift pump system integrated aquaculture raceway. Chao Yao et al. [30] studied the frictional pressure drop of air-water two-phase flows in vertically-downward tubes. Deendarlianto et al. [31] found the volume of solid particles raised by the pneumatic lifting system with a microbubble generator is much more compared with the traditional pneumatic lifting system. My group [32,33] discussed the influence of pneumatic lifting pump on natural circulation capability of the accelerator-driven sub-critical reactor. Ligus G. et al. [34] studied experimental optimization of an airlift pump with the use of image analysis. In summary, scholars have done much research on pneumatic lifting pumps, but little research has been done on the performance of pneumatic lifting pumps under different intake modes. Therefore, through an experimental study, this paper focuses on comparing the influence of different riser diameters and different air intake modes on the lifting performance of a lifting pump. Theoretical analysis is carried out and the theoretical calculation results and experimental results are compared and verified.

\section{Experimental Devices and Procedures}

Figure 1 is the experimental device of a pneumatic lifting pump. The ambient environment is normal temperature and pressure. The compressed air generated by the compressor removes moisture and oil stains through a dryer, enters the riser through a nozzle, and drives the water in the riser upward. The initial water level in the pipe is controlled by the level control box. After the air-water pass through the gas-liquid separation box on the upper part of the riser, the liquid enters the measurement tank (bucket) along the descending pipe. In addition, three kinds of nozzles with an intake area of 100, 50 , and $25 \mathrm{~mm}^{2}$ are designed. For each intake area, three injection methods are adopted. The intake area nozzle diagram is shown in Figure $1 b$. 


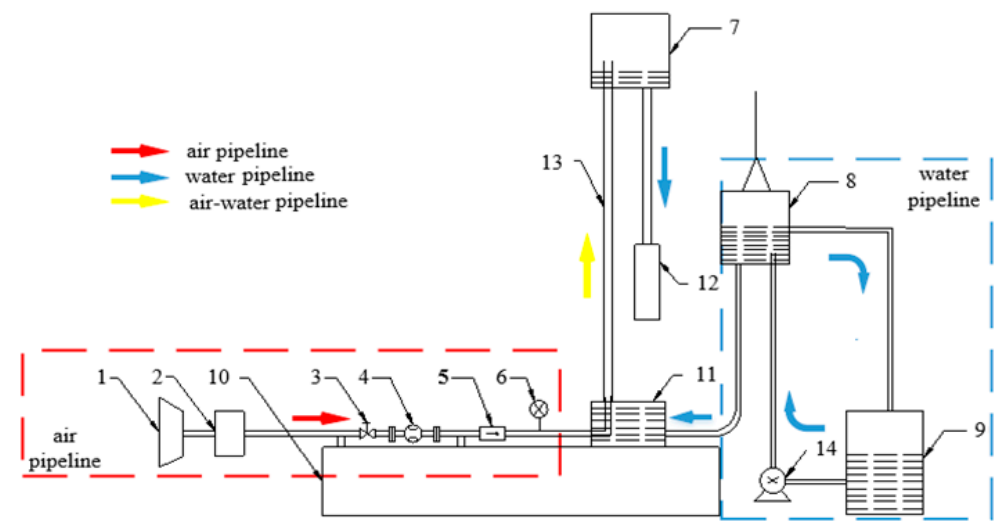

(a)
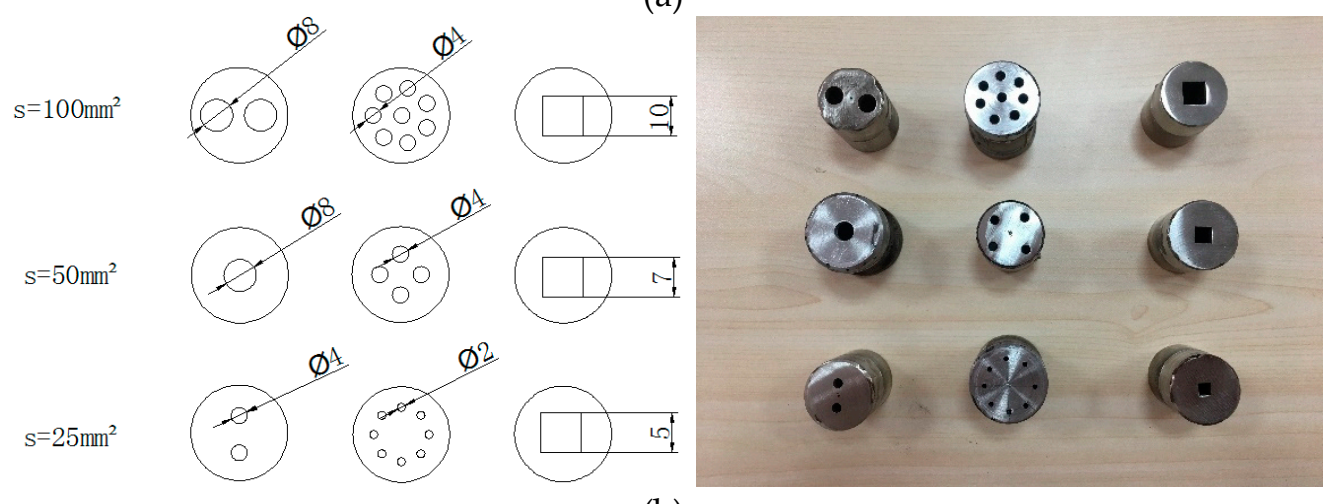

(b)

Figure 1. Experimental device of a pneumatic lifting pump. (a) The experimental overall frame: 1. air compressor, 2. dryer, 3. needle valve, 4 . flowmeter, 5. check valve, 6. pressure gauge, 7. gas-liquid separator, 8. level control box, 9. storage tank, 10. base, 11. nozzle, 12. measurement tank, 13. riser, 14. water pump. (b) Diagram of nozzles with three different inlet areas.

In this experiment, an LGYT series fuel-injection screw air compressor was used for air supply with an exhaust volume of $1.7 \mathrm{~m}^{3} / \mathrm{min}$ and exhaust pressure of $0.8 \mathrm{MPa}$. With a target to observe the change of flow pattern in the pipe, a visualization experiment was carried out by using a CCD (Charge Coupled Device) high-speed camera (LaVision Company, Göttingen, Germany). The frequency is $2000 \mathrm{fps}$, resolution is $1280 \times 1024$, the distance between the camera and object is $50 \mathrm{~cm}$, and the type of lens is C-Mount. The length of the riser was $1500 \mathrm{~mm}$; the diameters of the riser are $30 \mathrm{~mm}, 40 \mathrm{~mm}$, and $50 \mathrm{~mm}$. A water cover was added to the riser, which effectively reduced the optical distortion caused by shooting the flow pattern. The air flow in the pipeline was controlled by a needle valve. The LUXZ intelligent swirl gas flowmeter was used to record the instantaneous air intake in the pipeline. The flow rate range of the flowmeter was $1.2-15 \mathrm{~m}^{3} / \mathrm{h}$, the nominal pressure was $1.6 \mathrm{MPa}$, and the accuracy was 1.0 grade. The pneumatic pressure gauge was YC-100 marine pressure gauge. The measuring pressure range was $0.0-1.0 \mathrm{MPa}$ and the precision grade was 1.6 grade. In order to prevent the liquid in the riser from flowing back into the gas pipeline, a check valve was installed in the front of the nozzle. In the experiment, a stopwatch was used to record the working time of the pneumatic lifting pump, and an electronic scale was used to weigh the liquid flowing into the bucket. Finally, the lifting liquid flow rate of the pneumatic lifting pump was gained.

In this paper, the experimental tests of lifting pump with nine kinds of nozzles are carried out, when the riser diameter is $40 \mathrm{~mm}$. Additionally, the hydraulic characteristics of the lifting pump with three pipe diameters are studied when the nozzle is $\Phi 8 \mathrm{~mm} \times 1$. At the same time, the gas-liquid two-phase flow in the riser is captured by a high-speed camera to explore the development of flow field and the law of bubble motion in the riser. 


\section{Data Analysis}

\subsection{Effect of Intake Mode on the Performance of Pneumatic Lifting Pump}

\subsubsection{Hydraulic Characteristic Analysis of $8 \mathrm{~mm}$-wide Circular Hole Nozzle}

The basic performance index of a pneumatic lifting pump is the flow of lifted liquid. Figure 2 shows the curves of liquid flow rate with air intake when an $8 \mathrm{~mm}$-wide circular hole nozzle is used. By adjusting the height of the worm wheel and worm in Figure 1a, the initial liquid level height in the riser can be adjusted. The submergence ratio is the ratio of the initial liquid level in the riser to the height of the riser.

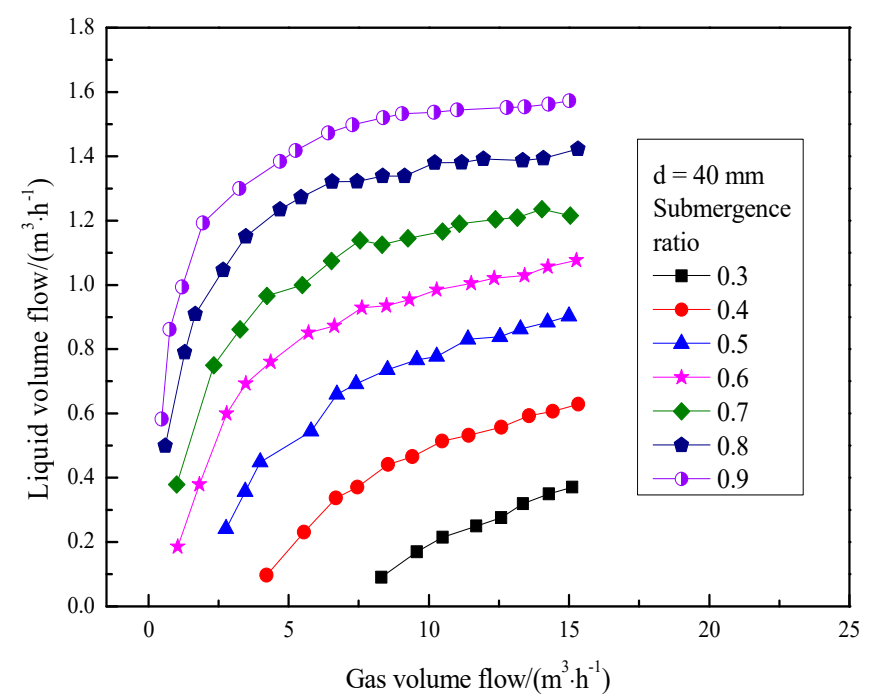

Figure 2. Changes of liquid flow with gas flow using $8 \mathrm{~mm}$-wide circular holes.

Figure 2 shows that with an increase in the gas volume flow rate (working condition), the liquid volume flow rate increases rapidly in the initial stage, and when the gas flow rate exceeds a certain value, the liquid flow rate tends to be stable. In addition, with the increase of submergence ratio, the flow rate of lifting liquid increases continuously.

The efficiency of a pneumatic lifting pump is the key factor to evaluate its lifting ability. According to the working principle of a pneumatic lifting pump, the efficiency $\eta$ should be the ratio of water mass flow rate to air mass flow rate [35].

$$
\eta=\frac{m_{L}}{m_{g}}
$$

In the formula, $m_{L}$ is liquid mass flow rate, $\mathrm{kg} / \mathrm{s} ; m_{g}$ is gas mass flow rate, $\mathrm{kg} / \mathrm{s} ; \eta$ is the efficiency of the pneumatic lifting pump.

Figure 3 shows the efficiency curve of the lifting pump with an $8 \mathrm{~mm}$-wide circular nozzle at different submergence ratios. It can be seen from the graph that when the submergence ratio is between 0.3 and 0.6 , the peak efficiency of the lifting pump increases with the increase of the submergence ratio, and the peak point moves forward continuously while the corresponding air flow decreases continuously; when the submergence ratio is between $0.7,0.8$, and 0.9 , the lifting efficiency curve decreases continuously with the increase of air flow, and there is no peak value. This is because the gas flow rate at the peak efficiency is too small, exceeds the flow measurement range used in the experiment, and it is difficult to collect the corresponding data. The flow pattern at the peak is a transition state from slug flow to churn flow. The forward movement of the peak point indicates that the transition of flow pattern occurs earlier in the pipe. 


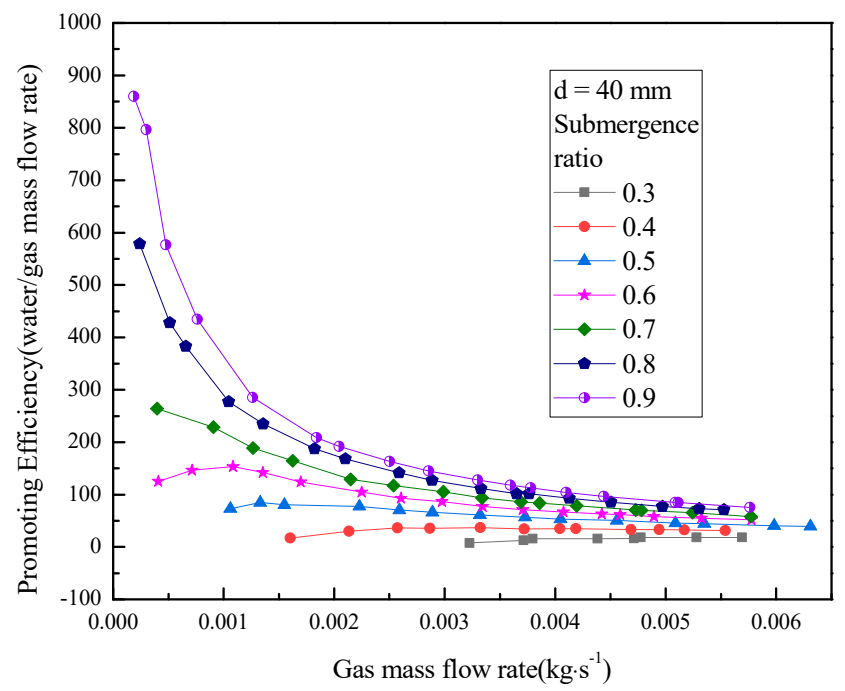

Figure 3. Changes of promoting efficiency with gas flow using $8 \mathrm{~mm}$-wide circular holes.

\subsubsection{Analysis of Hydraulic Characteristics of Different Nozzles}

Each nozzle in Figure 1b is tested separately, and the relationship between the air flow rate and the liquid flow rate of the lifting pump is obtained as shown in Figure 4. When the intake area is 100 and $50 \mathrm{~mm}^{2}$, the intake area has little influence on the liquid lift. When the intake area is $25 \mathrm{~mm}^{2}$, with the increase of air flow, the liquid lift is significantly higher than that of other nozzles. Parker pointed out that this is due to the increase of momentum of the gas inlet [36]. Further study shows that the air pressure increases slowly with the increase of air flow rate in the intake area of 100 and $50 \mathrm{~mm}^{2}$, but increases rapidly with the increase of air flow rate in the use of nozzles with the intake area of $25 \mathrm{~mm}^{2}$, as shown in Figure 5. This is because the flow area of the nozzle is too small, and the high-speed airflow cannot pass in time.

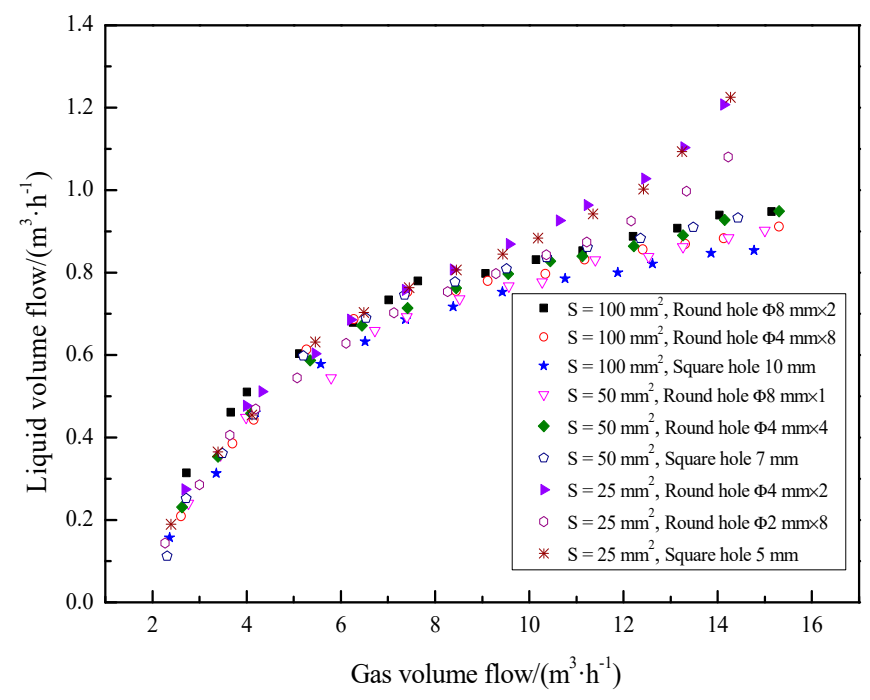

Figure 4. Changes of liquid flow gas flow under different intake modes at submergence Ratio of 0.5. 


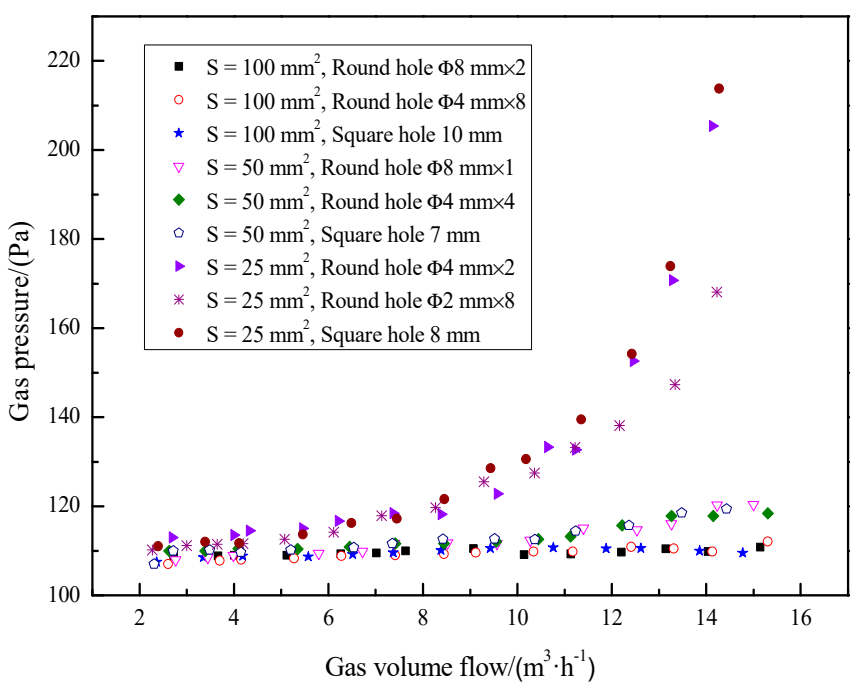

Figure 5. Change of gas pressure with gas flow rate at submergence ratio of 0.5 .

Figure 6 compares the lifting efficiency with the air flow rate under three different air intake areas; it can be seen that different air intake areas have a significant impact on lifting efficiency. The smaller the air intake area, the lower the lifting efficiency of the lifting pump. In addition, under the same air intake, with the gas mass flow rate increasing, the promoting efficiency increases initially and decreases later. This is because when the gas flow rate is small, the gas exists in the form of small bubbles, and the gas content in the pipe is low. With a greater gas flow rate, the gas content in the pipe increases, the dispersed small bubbles polymerize into slug bubbles. Thus, in the bubble flow and slug flow, with the gas flow rate increasing, the liquid is lifted more and more, and the efficiency continues to rise up. However, as the gas flow rate is continuously greater, the pipe flow patterns transform from slug flow to churn flow and annular flow, the gas content becomes bigger and bigger, leading to the liquid content declining in the pipe. Thus, at this period, although the gas flow rate increases, the lifting efficiency decreases.

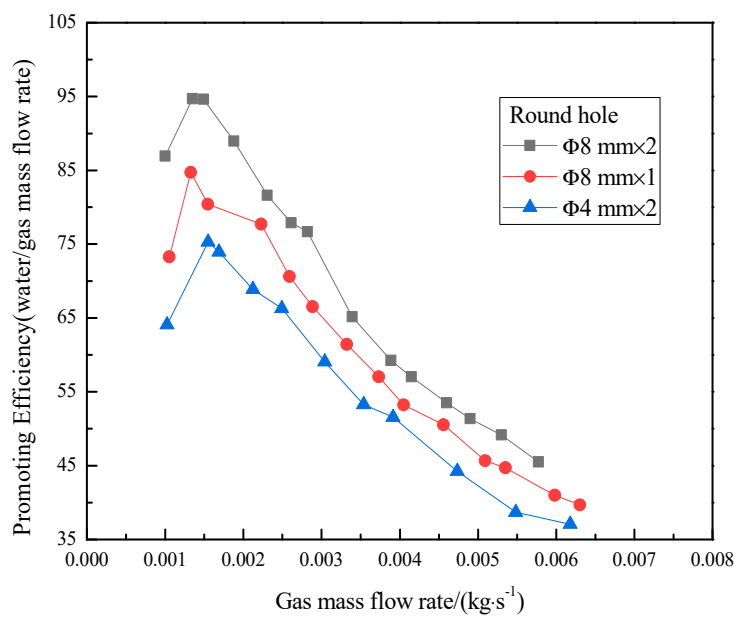

(a)

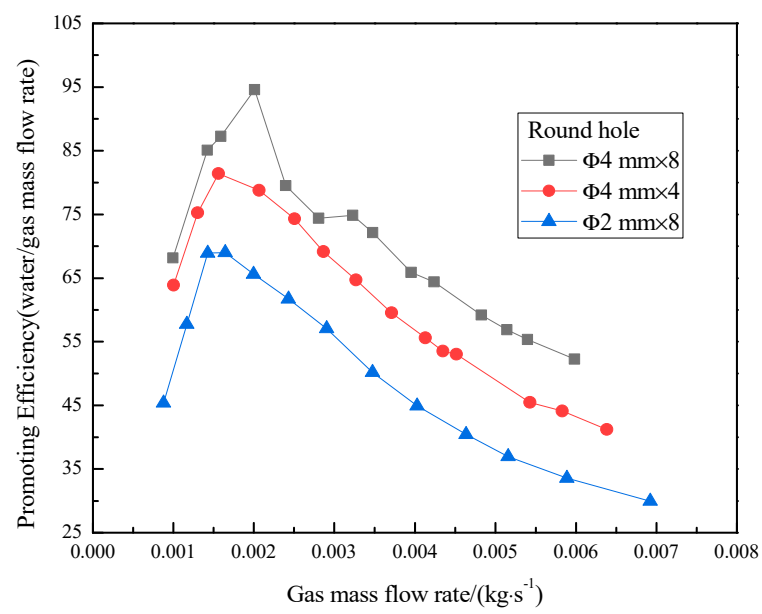

(b)

Figure 6. Cont. 


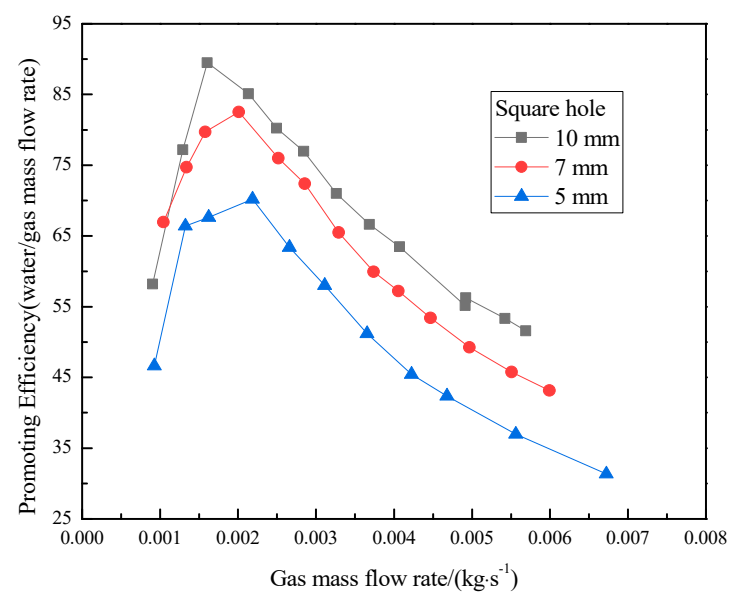

(c)

Figure 6. Changes of efficiency of lifting pumps with three different intake areas at submergence ratio of 0.5. (a) Intake area form I; (b) intake area form II; (c) intake area form III.

Figure 7 compares the lifting efficiency with the air flow rate under the same area and different air intake modes; it can be seen that under the same intake area, the different distribution of air holes has no significant effect on the lifting efficiency of the pump.

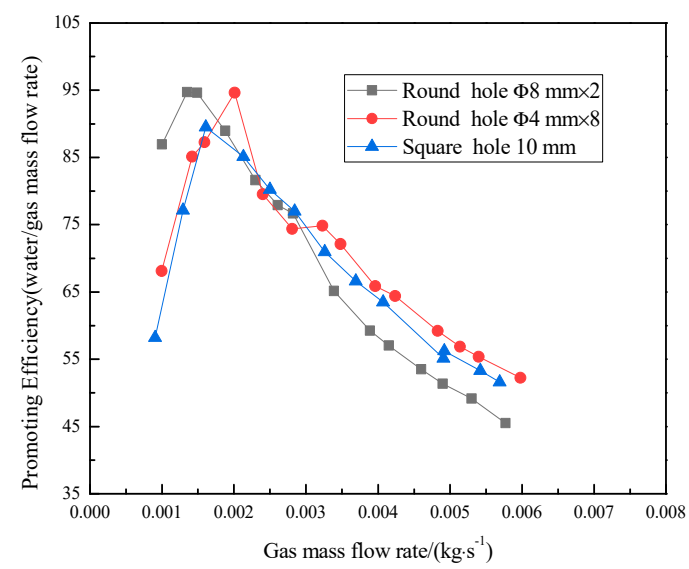

(a)

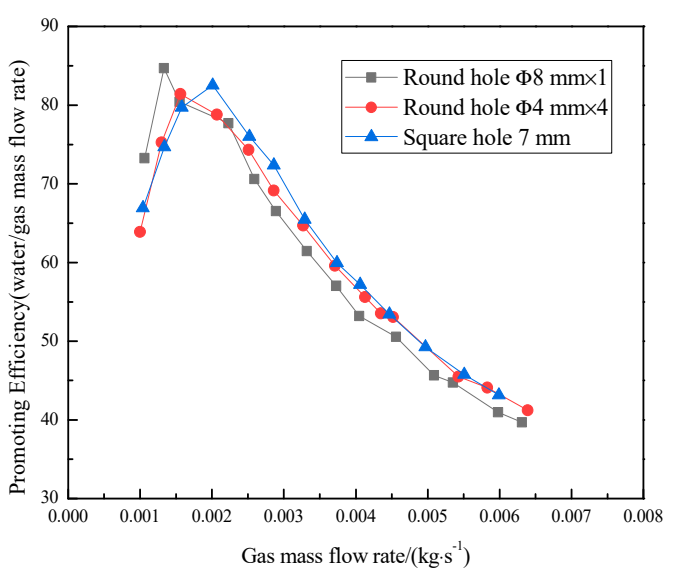

(b)

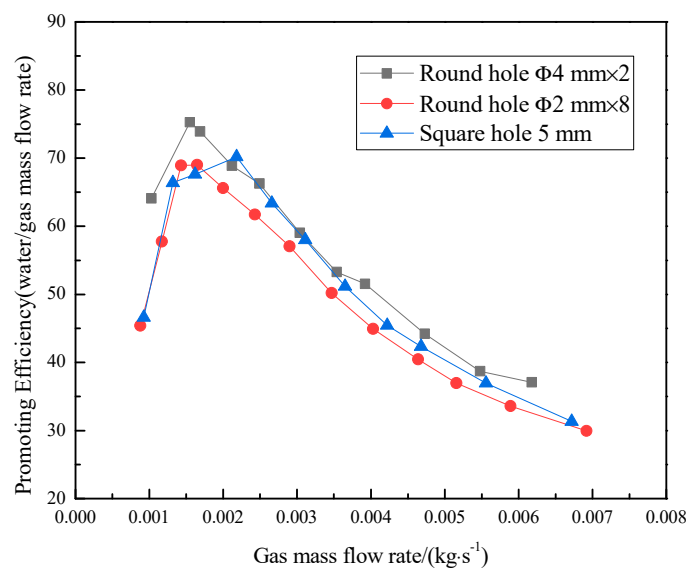

(c)

Figure 7. Changes of efficiency of lifting pumps with the same intake areas at submergence ratio of 0.5. (a) Intake area of $100 \mathrm{~mm}^{2}$; (b) intake area of $50 \mathrm{~mm}^{2}$; (c) intake area of $25 \mathrm{~mm}^{2}$. 


\subsection{Effect of Pipe Diameters on the Performance of Pneumatic Lifting Pump}

Figure 8 shows the variation curve of the liquid flow rate with air intake in a pneumatic lifting pump with an $8 \mathrm{~mm}$-wide circular nozzle, at submergence ratios of $0.5,0.6$, and 0.7 and pipe diameters of $30 \mathrm{~mm}, 40 \mathrm{~mm}$, and $50 \mathrm{~mm}$. It can be seen that at the same submergence ratio, the larger the pipe diameter, the higher the initial gas volume flow rate of liquid lifting. In the first half of the liquid lifting, the larger the pipe diameter, the smaller the volume flow of liquid; in the second half of the liquid lifting, the larger the pipe diameter, the larger the volume flow of liquid. The smaller the riser diameter, the smaller the final lifting capacity of the liquid.

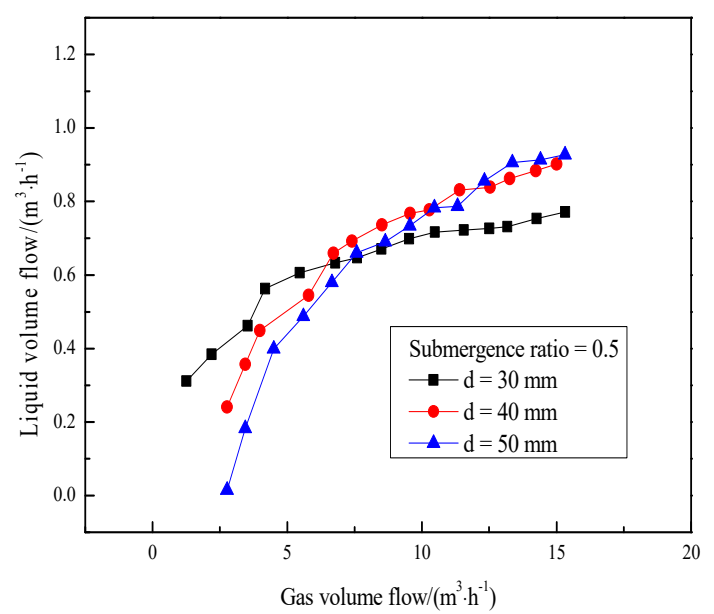

(a)

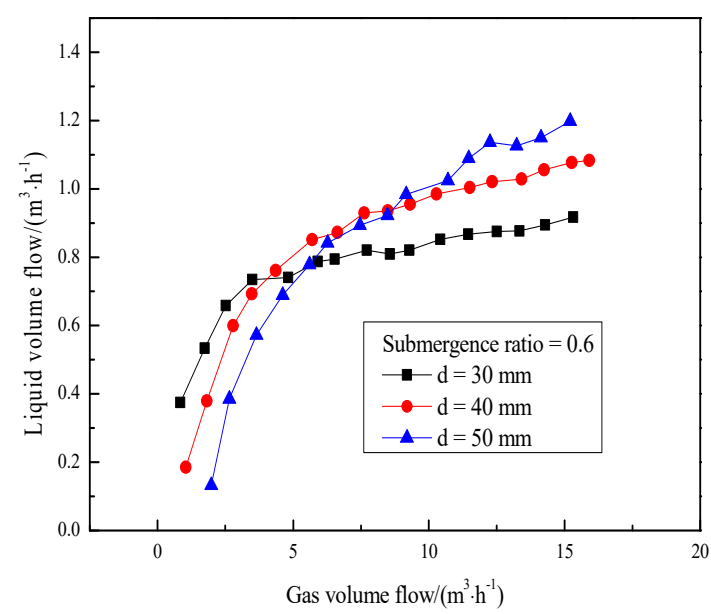

(b)

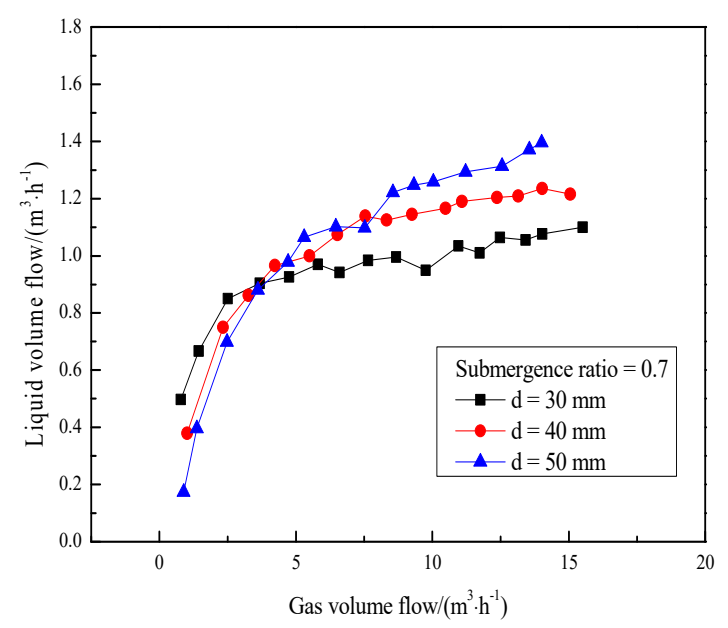

(c)

Figure 8. Changes of liquid flow with gas flow rate under different pipe diameters. (a) Submergence ratio of 0.5 ; (b) submergence ratio of 0.6 ; (c) submergence ratio of 0.7 .

Figure 9 shows the curve of the promoted efficiency of the pneumatic lifting pump with the intake gas volume under the use of an $8 \mathrm{~mm}$-wide circular nozzle when the submergence ratio is $0.5,0.6$, and 0.7 and the diameter of the pipe is $30 \mathrm{~mm}, 40 \mathrm{~mm}$, and $50 \mathrm{~mm}$. It can be seen that the smaller the riser diameter, the larger the lifting efficiency peak value, while the peak point moves forward continuously at the same submergence ratio. 


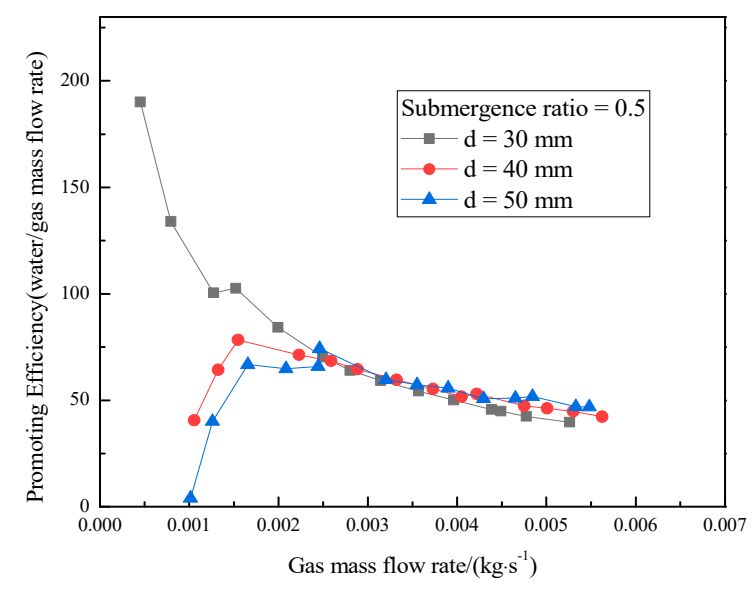

(a)

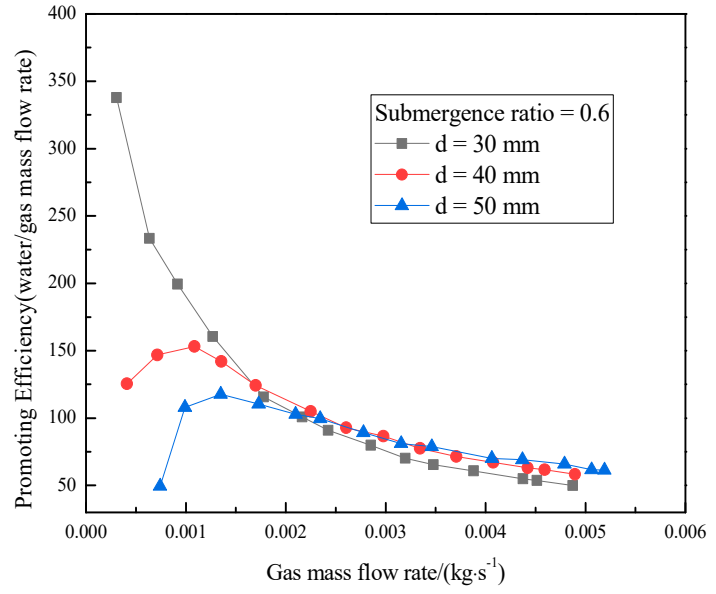

(b)

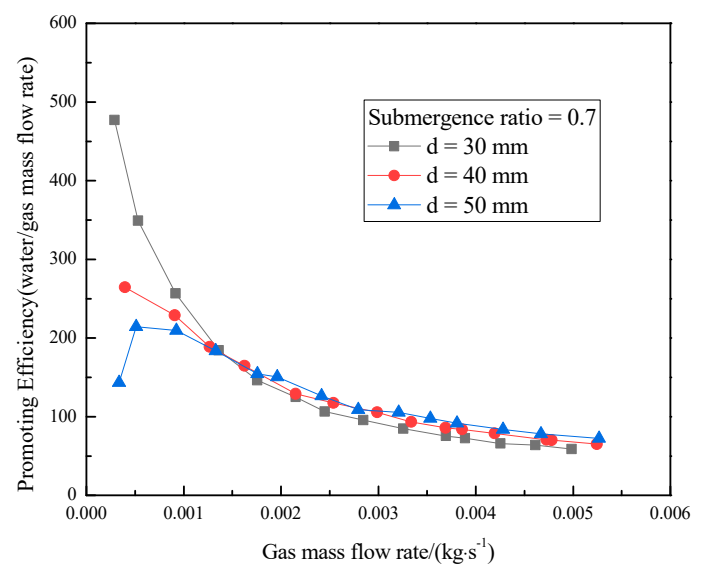

(c)

Figure 9. Changes of promoting efficiency with gas flow under different pipe diameters. (a) Submergence ratio of 0.5 ; (b) submergence ratio of 0.6 ; (c) submergence ratio of 0.7 .

\subsection{Analysis of Micro-Hydraulic Characteristics in Pipe}

\subsubsection{Analysis of Gas-Liquid Two-Phase Flow Patterns in Riser}

The flow in the pneumatic lifting pump is a complex gas-liquid two-phase flow, and different flow patterns have great influence on the performance of the lifting pump. In this paper, when the nozzle is $\Phi 8 \mathrm{~mm} \times 1$, the diameter of the riser is $40 \mathrm{~mm}$, the submergence ratio is 0.5 , and the variation of flow patterns in the pipe is gained by a high-speed camera.

When the gas flow rate is small, $Q_{g}$ is $2.765 \mathrm{~m}^{3} / \mathrm{h}, \mathrm{Q}_{l}$ is $0.241 \mathrm{~m}^{3} / \mathrm{h}$, the gas content in the pipe is low, and the gas phase only exists in the form of small bubbles in the liquid phase, as shown in Figure 10a. With the increase of gas flow, $Q_{g}$ is $3.990 \mathrm{~m}^{3} / \mathrm{h}, \mathrm{Q}_{l}$ is $0.449 \mathrm{~m}^{3} / \mathrm{h}$, the gas content in the pipe increases, and the dispersed small bubbles are gathered into slug bubbles, as shown in Figure 10b. At this time, the flow pattern is relatively stable with high lifting efficiency. As the gas flow rate is continuously increased, the gas phase loses its original stable form, the gas mixes with liquid, and the two-phase turbulence is intense. At this time, $Q_{g}$ is $9.567 \mathrm{~m}^{3} / \mathrm{h}, \mathrm{Q}_{l}$ is $0.767 \mathrm{~m}^{3} / \mathrm{h}$, and the flow pattern is a churn flow, as shown in Figure 10c. When the gas flow rate reaches the maximum, $Q_{g}$ is $15.002 \mathrm{~m}^{3} / \mathrm{h}$, $\mathrm{Q}_{l}$ is $0.902 \mathrm{~m}^{3} / \mathrm{h}$, the liquid content in the riser is extremely low, and the liquid mainly consists of liquid film attached to the pipe wall. The gas forms a high-speed gas column in the center of the riser, which drives the liquid near the pipe wall to move upward. The flow pattern in the pipe is annular flow, as shown in Figure 10d, and the vibration of the lifting pump is intense with a loud noise and low efficiency. 


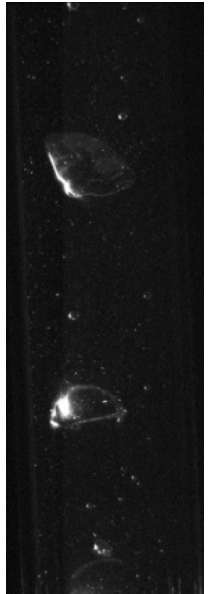

(a)

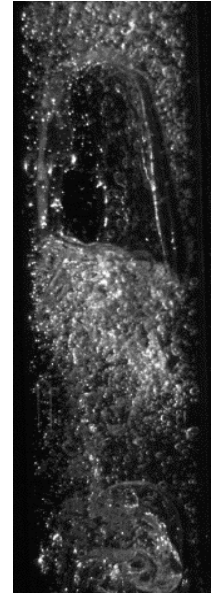

(b)

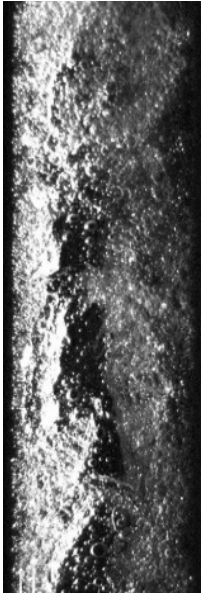

(c)

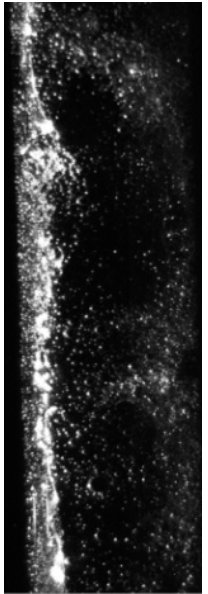

(d)

Figure 10. Flow pattern in the riser. (a) Bubbly flow; (b) slug flow; (c) churn flow; (d) annular flow.

\subsubsection{Motion Characteristics of Bubble Formation at Nozzle}

For the gas-liquid two-phase flow in a pneumatic lifting pump, the study of the formation process of bubbles at the nozzle has important significance for exploring the development of the air-water two-phase flow in the riser. In this experiment, the bubble formation process at the nozzle is photographed when the submergence ratio is 0.25 and the air flow rate is $14.61 \mathrm{~m}^{3} / \mathrm{h}$. The flow pattern change chart is shown in Figure 11.

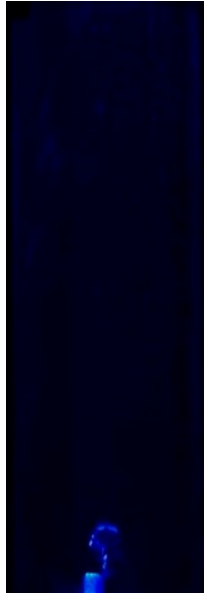

(a)

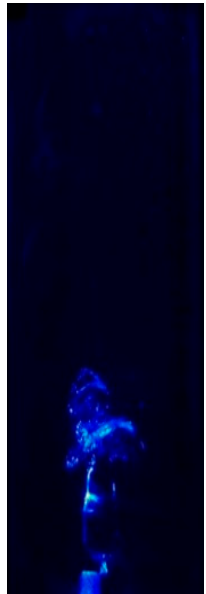

(b)

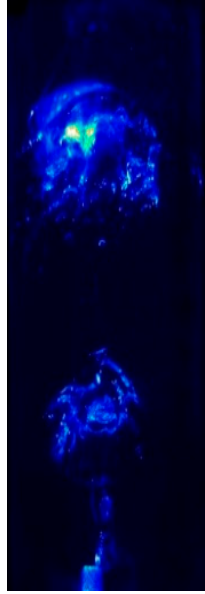

(c)

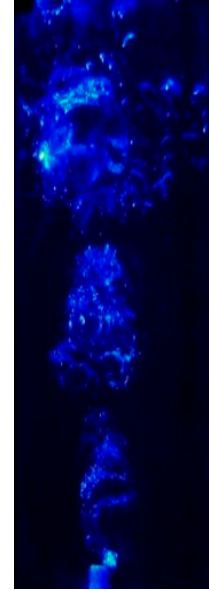

(d)

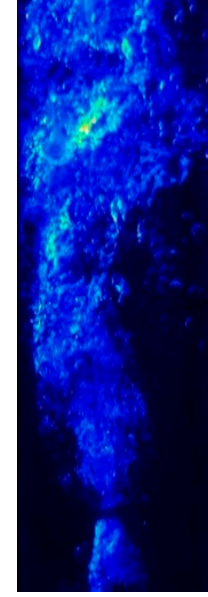

(e)

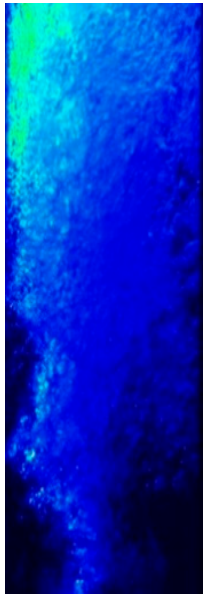

(f)

Figure 11. Bubble formation process at the nozzle. (a) $t=0.2 \mathrm{~s} ;(\mathbf{b}) \mathrm{t}=0.4 \mathrm{~s} ;(\mathbf{c}) \mathrm{t}=0.6 \mathrm{~s}$; (d) $\mathrm{t}=0.8 \mathrm{~s}$; (e) $\mathrm{t}=1.0 \mathrm{~s} ;(\mathbf{f}) \mathrm{t}=1.2 \mathrm{~s}$.

It can be seen from Figure 11a that when $t=0.2 \mathrm{~s}$, the gas begins to fill in the water, and the liquid phase has a low gas content, so only small bubbles are formed. In this stage, the bubbles attach to the wall of the edge of the nozzle, and the volume of bubbles increases with the increase of the filling volume of gas. As the gas enters continuously from the nozzle, the bubbles begin to leave the filling hole, and stretch to form a long neck and then move away from the hole. The small bubbles, which come from the hole, can gather into large slug bubbles, as shown in Figure 11b,c. At this time, the flow field is relatively stable. However, with the continuous accumulation of gas, the slug bubble eventually bursts and forms discrete small bubbles in the water. These discrete bubbles have different sizes and velocities and disperse in the liquid phase, disturbing the original stable flow field, as shown 
in Figure 11d,e. Finally, after $t=1.2 \mathrm{~s}$, it is difficult for the gas entering the water to gather into big bubbles due to the interference of discrete small bubbles, as shown in Figure 11f, which eventually leads to intense two-phase turbulence at the nozzle.

\section{Theoretical Analysis and Verification}

In this paper, the one-dimensional dimensionless equation of the pneumatic lifting pump proposed by Parker [36] is revised based on the slip ratio formula of gas-liquid two-phase under slug flow deduced by Griffith et al. [37]. The deduction process is as follows and the pneumatic lifting model is shown in Figure 12. The riser is inserted into the liquid and the free surface pressure is atmospheric pressure. The outlet of the intake pipeline is connected with the bottom of the riser.

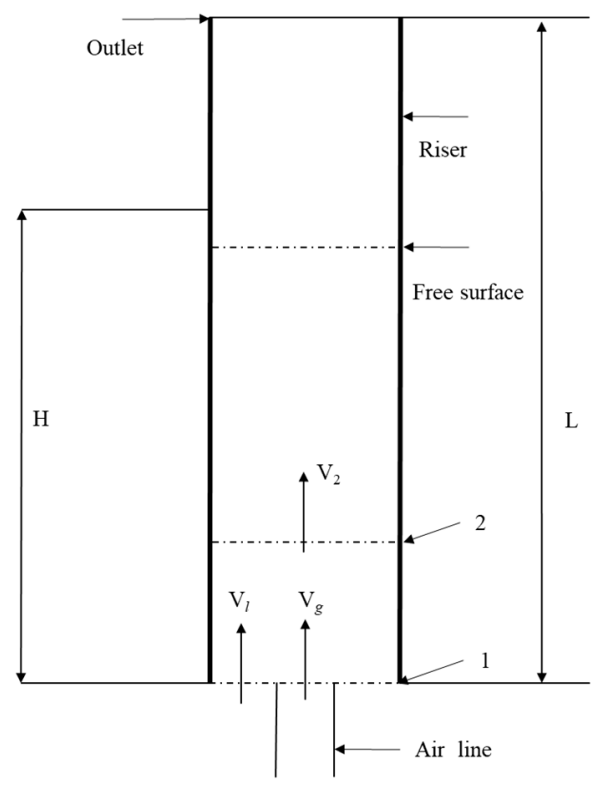

Figure 12. Theoretical model of pneumatic lifting pump.

In the modeling of the pneumatic lift pump, the riser is divided into two areas. The gas is injected into the riser through cross-section 1, then mixed with liquid, and lifted to the exit. The area between cross sections 1 and 2 is the gas-liquid mixing area, and the area between cross-section 2 and the exit of the riser is the gas-liquid fully-developed area.

The theoretical model of internal flow in the riser is finally obtained [36]:

$$
\frac{H}{L}-\frac{1}{\left[1+(1 / S) \cdot\left(Q_{g} / Q_{l}\right)\right]}=\frac{Q_{l}^{2}}{2 g L A^{2}}\left[(K+1)+(K+2) \frac{Q_{g}}{Q_{l}}-2 \frac{\rho_{g}}{\rho_{l}} \cdot \frac{A}{A_{g}}\left(\frac{Q_{g}}{Q_{l}}\right)^{2}\right]
$$

In the model, $L$ is the length of the riser, $\mathrm{m} ; A$ is the cross-sectional area, $\mathrm{m}^{2} ; H$ is the distance from the free surface to the bottom of the riser, $\mathrm{m} ; A_{g}$ is the cross-sectional area of the intake pipeline, $\mathrm{m}^{2}$; At the bottom of the air line, $V_{g}$ is the gas entry velocity, $\mathrm{m} / \mathrm{s}$; the liquid entry velocity is $V_{l}, \mathrm{~m} / \mathrm{s}$; and $V_{2}$ is the gas-liquid mixing velocity at cross-section $2, \mathrm{~m} / \mathrm{s} ; \rho_{l}$ is the liquid density, $\mathrm{kg} / \mathrm{m}^{3} ; Q_{l}$ is the volume flow rate of liquid, $\mathrm{m}^{3} / \mathrm{h} ; Q_{g}$ is the volume flow rate of gas, $\mathrm{m}^{3} / \mathrm{h} ; S$ is the slip ratio between phases; $K=4 f L / D$ and based on Parker's research results, when $A_{g}=0.63 A_{N}$, the theoretical value is more consistent with the experimental value and $A_{N}$ is the total area of the air holes of the nozzle [36].

$$
\frac{H}{L}-\frac{1}{\left[1+(1 / S) \cdot\left(Q_{g} / Q_{l}\right)\right]}=\frac{Q_{l}^{2}}{2 g L A^{2}}\left[(K+1)+(K+2) \frac{Q_{g}}{Q_{l}}-\frac{200 \rho_{g}}{63 \rho_{l}} \cdot \frac{A}{A_{N}}\left(\frac{Q_{g}}{Q_{l}}\right)^{2}\right]
$$


The calculation of slip ratio $S$ is based on the conclusions of Griffith et al. [37] under slug flow:

$$
S=1.2+0.2 \frac{Q_{g}}{Q_{l}}+\frac{0.35 \sqrt{g D}}{V_{l}}
$$

Friction coefficient $f$ is obtained by Colebrook [38] and verified by Haaland [39]:

$$
\frac{1}{\sqrt{f}}=-2.0 \log \left(\frac{\varepsilon / D}{3.7}+\frac{2.51}{\operatorname{Re} \sqrt{f}}\right)
$$

In order to verify the validity of the theoretical model, the experimental values are compared with the theoretical values when a riser diameter is $40 \mathrm{~mm}$, as shown in Figure 13. The experimental data used $\Phi 4 \mathrm{~mm} \times 8$ orifice of inlet area for $100 \mathrm{~mm}^{2}, \Phi 4 \mathrm{~mm} \times 4$ orifice of inlet area for $50 \mathrm{~mm}^{2}$, and $\Phi$ $2 \mathrm{~mm} \times 8$ of inlet area for $25 \mathrm{~mm}^{2}$.
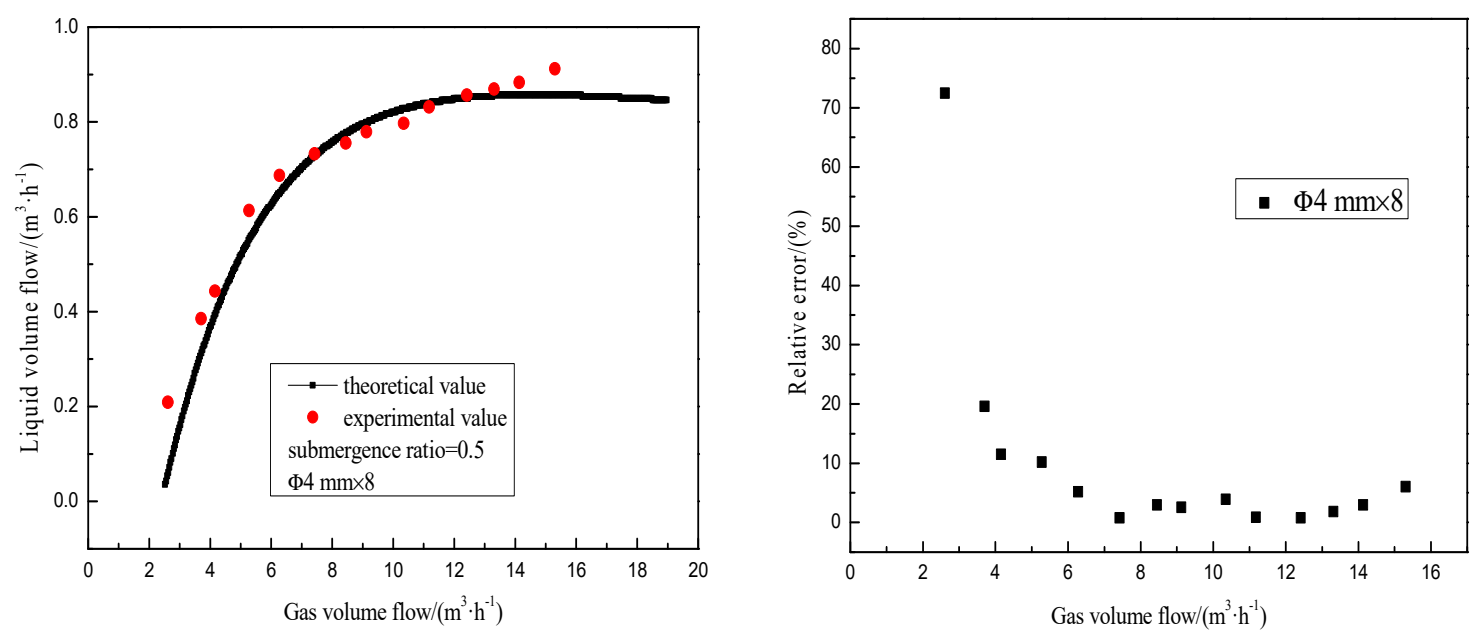

(a)
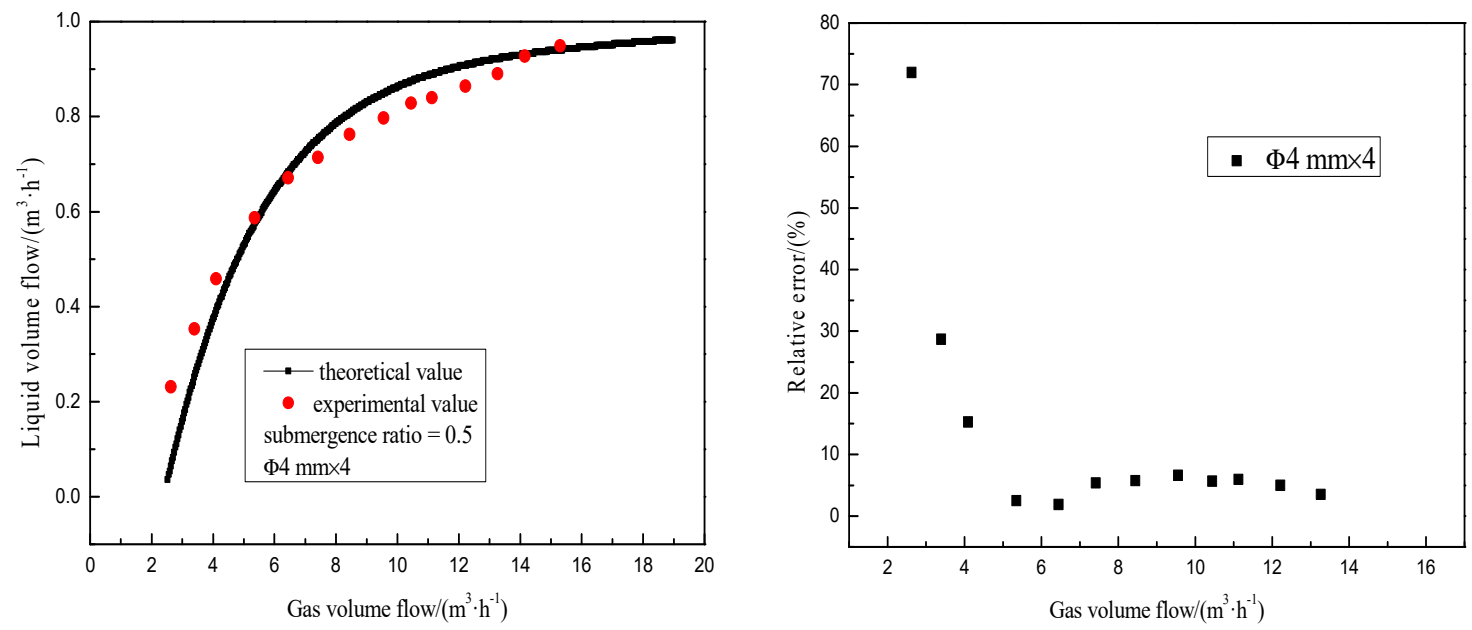

(b)

Figure 13. Cont. 


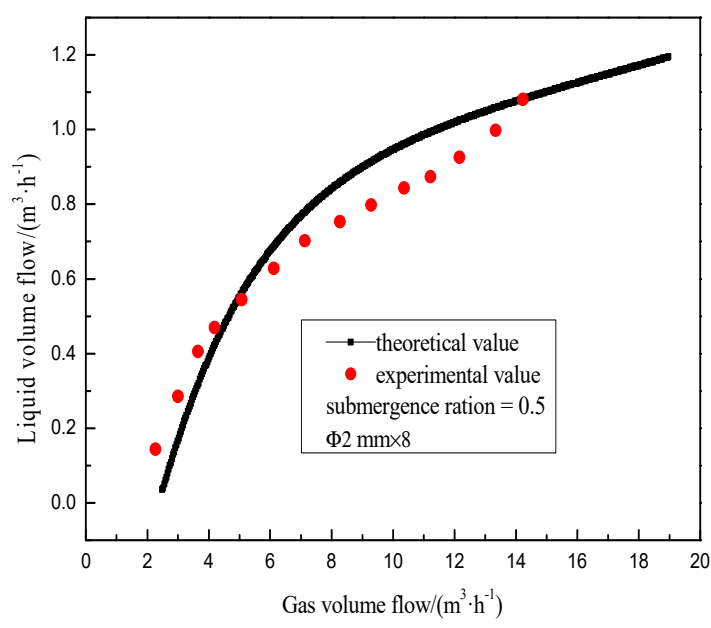

(c)

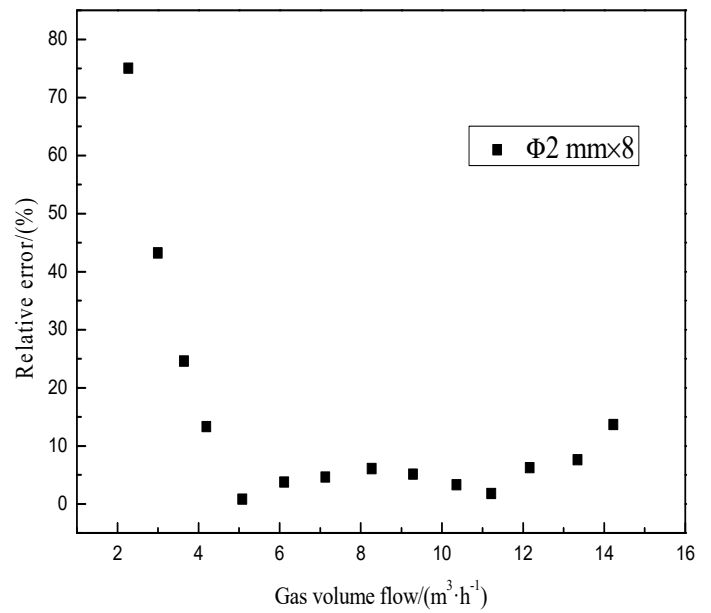

Figure 13. Comparison of experimental values and theoretical values at submergence ratio of 0.5 (a) Intake area of $100 \mathrm{~mm}^{2}$; (b) intake area of $50 \mathrm{~mm}^{2}$; (c) intake area of $25 \mathrm{~mm}^{2}$.

When the air intake is small, the relative error is very large; with the increase of the air intake, the relative error gradually reduces. Near the minimum value, the experimental values are in good agreement with the theoretical values, and the relative error is less than $5 \%$. When the air intake increases gradually, the relative error gradually rises to more than $5 \%$. The main reason is that the slip ratio formula used in this paper is based on conclusions gained by Griffith et al. [37] under slug flow. The closer the flow pattern is to slug flow, the smaller the error between the theoretical value and experimental value.

\section{Conclusions and Discussions}

The nine kinds of air intake modes and three kinds of riser diameters of a pneumatic lifting pump are designed, the hydraulic characteristics and gas-liquid two-phase flow on lifting performance are analyzed, and the theoretical model of a pneumatic lifting pump is established for comparison and verification. The following conclusions are drawn:

1. Under the intake mode with an $8 \mathrm{~mm}$-wide circular nozzle and diameter of riser with $40 \mathrm{~mm}$, as the air flow rate increases, the lifting liquid flow rate increases rapidly at first, then slows down gradually; the lifting efficiency increases rapidly at first, reaches the peak value, and then decreases.

2. When the riser diameter is $40 \mathrm{~mm}$, the submergence ratio is 0.5 , under different intake areas, smaller intake areas can promote the liquid flow rate, but reduce the lifting efficiency of the pneumatic lifting pump; under the same intake area, there is not significant influence on the liquid flow rate and lifting efficiency of the pneumatic lifting pump with the different air holes.

3. The experiment is carried out when the diameters of riser are $30 \mathrm{~mm}, 40 \mathrm{~mm}$, and $50 \mathrm{~mm}$, and the submergence ratios are $0.5,0.6$, and 0.7 , with an $8 \mathrm{~mm}$-wide circular nozzle. At the same submergence ratio, the smaller the diameter of the riser, the smaller the final lifting liquid flow rate and the larger the lifting efficiency peak value.

4. When the flow pattern in the pipe is slug flow, the theoretical model better predicts the lifting flow rate of the lifting pump; but when the flow pattern in the pipe is other flow pattern, the error between the theoretical value and the experimental value is large with the relative error gradually rising to more than $5 \%$. 
Author Contributions: Conceptualization, J.Z. (Juanli Zuo); data curation, J.Z. (Juanli Zuo), F.L., and N.Z.; formal analysis, J.Z. (Juanli Zuo) and N.Z.; funding acquisition, J.Z. (Juanli Zuo), N.Z., D.H., W.W., and J.Z. (Jie Zhang); investigation, F.L. and N.Z.; project administration, J.Z. (Juanli Zuo); validation, F.L.; visualization, F.L.; writing-original draft, J.Z. (Juanli Zuo), F.L., and N.Z.; writing-review and editing, D.H., W.W., and J.Z. (Jie Zhang). All authors have read and agreed to the published version of the manuscript.

Funding: This research was funded by the National Natural Science Foundation of China $(11605136,51709227$, 51609198, 21606176), and the National Science and Technology Major Project of China (2017ZX04011010).

Acknowledgments: We thank Bingqian Wei for editing the English text of this manuscript.

Conflicts of Interest: The authors declare no conflicts of interest.

\section{Nomenclature}

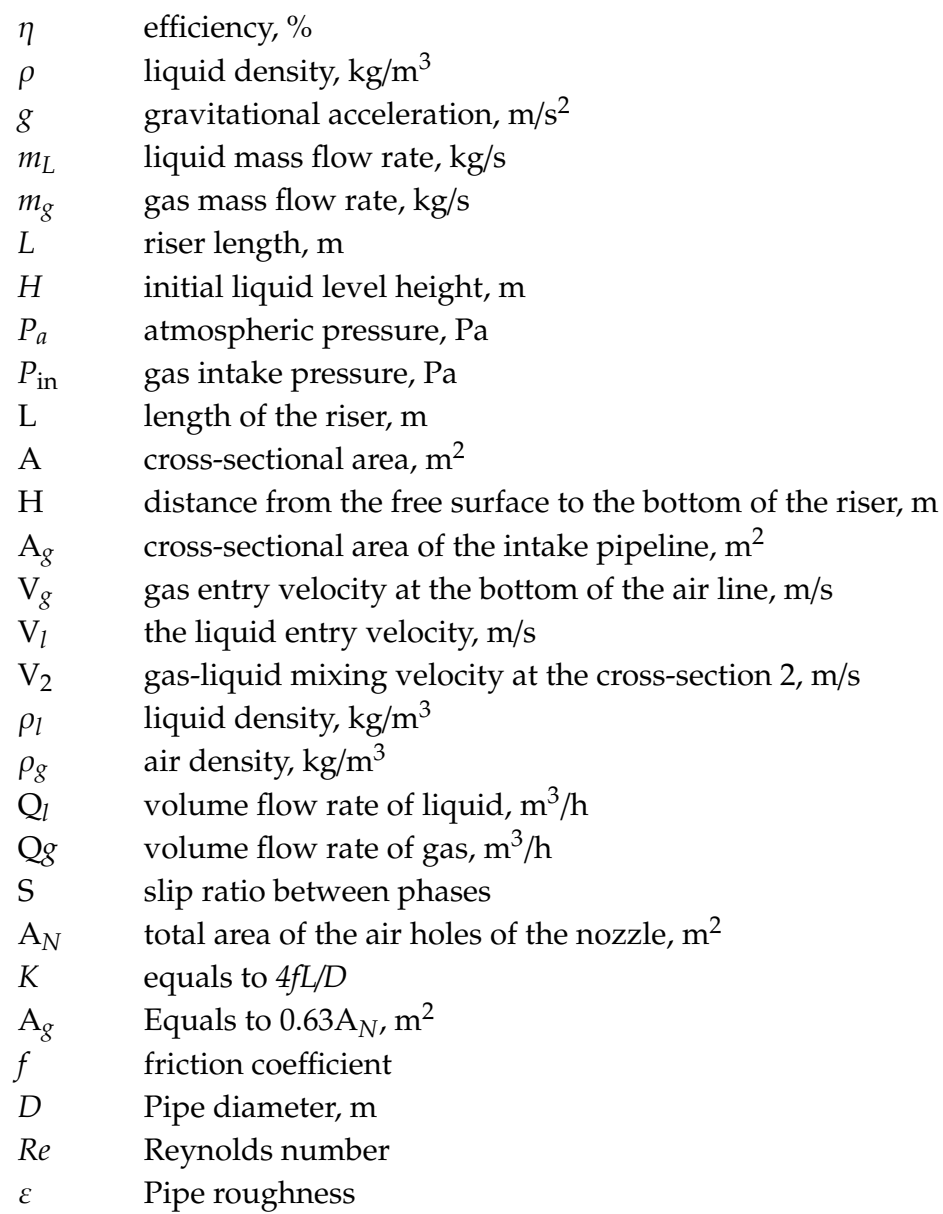

\section{References}

1. Kassab, S.Z.; Kandil, H.A.; Warda, H.A.; Ahmed, W.H. Experimental and analytical investigations of airlift pumps operating in three-phase flow. Chem. Eng. J. 2007, 131, 273-281. [CrossRef]

2. Castro, W.E.; Zielinski, P.B.; Sandifer, P.A. Performance characteristics of air lift pumps of short length and small diameter. J. World Aquacult. Soc. 1975, 6, 451-461. [CrossRef]

3. Kassab, S.Z.; Kandil, H.A.; Warda, H.A.; Ahmed, W.H. Air-lift pumps characteristics under two-phase flow conditions. Int. J. Heat Fluid Flow 2009, 30, 88-98. [CrossRef]

4. Hanafizadeh, P.; Ghanbarzadeh, S.; Saidi, M.H. Visual technique for detection of gas-liquid two-phase flow regime in the airlift pump. J. Pet. Sci. Eng. 2011, 75, 327-335. [CrossRef]

5. Pougatch, K.; Salcudean, M. Application of CFD methods to the analysis of the flow in air-lift pump. In Proceedings of the 26th International Conference on Offshore Mechanics and Arctic Engineering, San Diego, CA, USA, 10-15 June 2007. 
6. Pougatch, K.; Salcudean, M. Numerical modeling of deep sea air-lift. Ocean Eng. 2008, 35, 1173-1182. [CrossRef]

7. Esen, I.I. Experimental investigation of a rectangular air-lift pump. Adv. Civ. Eng. 2010, 11, 1-5.

8. Chan, K.W.; McCulloch, M. Analysis and modeling of water based bubble pump at atmospheric pressure. Int. J. Refrig. 2013, 36, 1521-1528. [CrossRef]

9. Hanafizadeh, P.; Saidi, M.H.; Karimi, A.; Zamiri, A. Effect of bubble size and angle of tapering up-riser pipe on the performance of airlift pumps. Particul. Sci. Technol. 2010, 28, 332-347. [CrossRef]

10. Hanafizadeh, P.; Karimi, A.; Saidi, M.H. Effect of step geometry on the performance of the airlift pump. Fluid Mech. Res. 2011, 38, 387-408. [CrossRef]

11. Moisidis, C.T.; Kastrinakis, E.G. Two-phase flow pattern transitions of short airlift pumps. J. Hydraul. Res. 2010, 48, 680-685. [CrossRef]

12. Moisidis, C.T.; Kastrinakis, E.G. Pressure behavior in riser tube of a short airlift pump. J. Hydraul. Res. 2010, 48, 65-73. [CrossRef]

13. Riglin, J. Performance characteristics of airlift pumps with vortex induced by tangential fluid injection. Honors Theses, Bucknell University, Lewisburg, PA, USA, 2011.

14. Sun, B.; Sun, L.; Liu, J.; Tian, D. Study on void fraction of vertical gas-liquid two-phase flow in a relatively large diameter pipe. Chinese J. Hydrodynam. 2012, 27, 1-6.

15. Liu, M. Effect of local pipe bends on airlift pump performance and study of flow pattern. Master Degree Thesis, Hunan University of Technology, Hunan, China, 2014.

16. Hu, D.; Tang, C.-L.; Cai, S.P.; Zhang, F.-H. The Effect of Air Injection Method on the Airlift Pump Performance. J. Fluids Eng. 2012, 134, 111302. [CrossRef]

17. Zou, W.; Lu, Y.; Li, Z. Numerical Simulation and Analyses of Lift Pump in Deep Sea Mining. J. Hunan Univ. 2013, 40, 59-63.

18. Wahba, E.M.; Gadalla, M.A.; Abueidda, D.; Dalaq, A.; Hafiz, H.; Elawadi, K.; Issa, R. On the Performance of Air-Lift Pumps: From Analytical Models to Large Eddy Simulation. J. Fluids Eng. 2014, 136, 111301. [CrossRef]

19. Hosokawa, S.; Fujimoto, S.; Tomiyama, A. Gaslift pump making use of phase change of working fluid. Appl. Therm. Eng. 2016, 103, 1119-1125. [CrossRef]

20. Xue, Y.; Li, H.; Hao, C.; Yao, C. Investigation on the void fraction of gas-liquid two-phase flows in vertically-downward pipes. Int. Commun. Heat Mass Transf. 2016, 77, 1-8. [CrossRef]

21. Xue, Y.Q.; Li, H.X.; Chao, Y.; Hao, C.Y.; Guo, K.K.; Feng, Y. Investigation of flow pattern transition of bubbly flow-slug flow for two-phase flows in the vertical downwards pipes. Chinese J. Appl. Mech. 2017, 34, 603-609.

22. Fu, S.T. Study on Flow Pattern Identification Based on Wavelet Analysis for air-lifting system. Master Degree Thesis, Hunan University of Technology, Hunan, China, 2017.

23. Oueslati, A.; Megriche, A. The effect of liquid temperature on the performance of an airlift pump. Energy Procedia 2017, 119, 693-701. [CrossRef]

24. An, L.; Liu, D.; Chen, Y.; Yang, L.; Yang, M.; Lin, F. Theoretical and experimental study on the lifting performance of bubble pump with variable cross-section lift tube. Appl. Therm. Eng. 2017, 111, 1265-1271. [CrossRef]

25. Wang, Z.; Kang, Y.; Wang, X.; Li, D.; Hu, D. Investigating the flow characteristics of air-lift pumps operating in gas-liquid two-phase flow. Chinese J. Chem. Eng. 2018, 26, 219-227. [CrossRef]

26. Shi, L.; Tan, B.; Wang, C.; Tian, W.; Qiu, S.; Wu, J.; Su, G.H. Experimental investigation of gas lift pump in lead-bismuth eutectic loop. NucL. Eng. Des. 2018, 330, 516-523. [CrossRef]

27. Chen, Q.L.; Wu, S.J.; Li, X.Y.; Wang, A.H. Experimental study on sediment transport in river channel based on pneumatic lifting technology. J. Drain. Irrig. Mach. Eng. 2018, 36, 397-403.

28. Qiang, Y.F.; Fan, W.; Xiao, C.B.; Pan, Y.W.; Chen, Y. Effects of operating parameters and injection method on the performance of an artificial upwelling by using airlift pump. Appl. Ocean Res. 2018, 78, $212-222$. [CrossRef]

29. Shallouf, M.; Ahmed, W.H.; Abdou, S. Engineered-airlift pumps for aquaculture applications using multiphase flow analysis. Aquac. Eng. 2019, 87, 101998. [CrossRef]

30. Yao, C.; Li, H.X.; Xue, Y.Q.; Liu, X.; Hao, C.Y. Investigation on the frictional pressure drop of gas liquid two-phase flows in vertical downward tubes. Int. Commun. Heat Mass Transf. 2018, 91, 138-149. [CrossRef] 
31. Deendarlianto; Supraba, I.; Majid, A.I.; Pradecta, M.R.; Indarto; Widyaparaga, A. Experimental investigation on the flow behavior during the solid particles lifting in a micro-bubble generator type airlift pump system. Case Stud. Therm. Eng. 2019, 13, 100386. [CrossRef]

32. Zuo, J.; Tian, W.; Chen, R.; Qiu, S.; Su, G. Research on enhancement of natural circulation capability in lead-bismuth alloy cooled reactor by using gas-lift pump. Nucl. Eng. Des. 2013, 263, 1-9. [CrossRef]

33. Zuo, J.; Tian, W.; Qiu, S.; Su, G. Transient safety analysis for simplified accelerator driven system with gas-lift pump. Prog. Nucl. Energy 2018, 106, 181-194. [CrossRef]

34. Ligus, G.; Zając, D.; Masiukiewicz, M.; Anweiler, S. A New Method of Selecting the Airlift Pump Optimum Efficiency at Low Submergence Ratios with the Use of Image Analysis. Energies 2019, 12, 735. [CrossRef]

35. Hanafizadeh, P.; Raffiee, A.H.; Saidi, M.H. Experimental investigation of characteristic curve for gas-lift pump. J. Pet. Sci. Eng. 2014, 116, 19-27. [CrossRef]

36. Parker, G.J. The effect of footpiece design on the performance of a small air lift pump. Int. J. Heat Fluid Flow 1980, 2, 245-252. [CrossRef]

37. Giffith, P.; Wallis, G.B. Two-Phase slug flow. ASME J. Heat Transf. 1961, 83, 307. [CrossRef]

38. Colebrook, C.F.; Blench, T.; Chatley, H.; Essex, E.H.; Finniecome, J.R.; Lacey, G.; Williamson, J.; Macdonald, G.G. Turbulent flow in pipes with particular reference to the transition region between the smooth and rough pipe laws. J. Inst. Civ. Eng. 1939, 12, 393-422. [CrossRef]

39. Haaland, S.E. Simple and explicit formulas for the friction factor in turbulent flow. J. Fluids Eng. 1983, 105, 89-90. [CrossRef]

(C) 2020 by the authors. Licensee MDPI, Basel, Switzerland. This article is an open access article distributed under the terms and conditions of the Creative Commons Attribution (CC BY) license (http://creativecommons.org/licenses/by/4.0/). 